\title{
Effects of Home Voice Assistants' Autonomy on Instrusiveness and Usefulness: Direct, Indirect, and Moderating Effects of Interactivity
}

\author{
Laura Lucia-Palacios * \& Raúl Pérez-López \\ Faculty of Economics and Business Administration, Department of Marketing, University of Zaragoza (Spain), Gran Via 2, 50.005 Zaragoza, Spain
}

Editor: Dr W Moe

\begin{abstract}
This research investigates whether interactivity of home voice assistants can reduce the consumer's perceptions of intrusiveness when using these products because of their autonomy. To do so, the authors applied structural equation modeling to 607 questionnaires. The results show that autonomy has a quadratic effect on intrusiveness and usefulness, being more intense for high levels of autonomy. Interactivity reduces intrusiveness both directly and indirectly through brand trust, and interactivity has a positive effect on usefulness. Furthermore, interactivity moderates the effect of autonomy on intrusiveness. These results lead to interesting managerial implications, such as the inclusion of interactive characteristics in smart products to enable consumers to control and communicate with them.

(C) 2021 Direct Marketing Educational Foundation, Inc. dba Marketing EDGE. This is an open access article under the CC BY-NC-ND license (http://creativecommons.org/licenses/by-nc-nd/4.0/).
\end{abstract}

Keywords: Autonomy; Interactivity; Intrusiveness; Brand trust; Smart products; Usefulness

\section{Introduction}

The use of the Internet of things in household products is becoming more common. According to a study by Accenture (2019), smart speakers are one of the fastest-adopted technologies in US history, and $93 \%$ of consumers globally expect their home device purchases, such as smart TVs or computers, to be based on ease of integration with their standalone smart speaker. Millions of smart speakers, such as Alexa, Siri, Google Home, or Cortana, have been sold, and worldwide spending on these devices is expected to reach $\$ 2$ billion by 2020 (Gartner, 2016).

These speakers are autonomous: They are able to interact with users and other devices freely and independently (Hoffman \& Novak, 2015). This characteristic can explain smart products' usefulness. In a smart home system, an autonomous speaker can

\footnotetext{
* Corresponding Author.

E-mail addresses: 1lucia@unizar.es (L. Lucia-Palacios), raperez@unizar.es (R. Pérez-López).
}

put users in contact with other devices, centralizing the users' commands and doing routine tasks more efficiently (Mani \& Chouk, 2017; Rijsdijk \& Hultink, 2009). Although autonomy has advantages, a very high level of this characteristic can increase perceived performance risks and failure severity, and academia and practitioners need more research to understand the effect of autonomy on usefulness (Verhoef et al., 2017).

To increase their usefulness, home voice assistants use voice control and respond to some words to awake the smart home assistant. The speakers' microphone has to be continuously listening and collecting data, and sometimes it activates unintentionally. For that reason, intrusiveness is a characteristic of this product (Benlian, Klumpe, \& Hinz, 2019; Hoffman \& Novak, 2015). Intrusiveness implies a loss of privacy, which has led to a public debate about the risks of these smart products, the negative impact that intrusiveness has on their brand image, and decreasing trust in the providers. Due to intrusiveness, these smart home assistants generate stress and domestic conflict among family members (Benlian et al., 2019) 
who feel that technology invades their privacy (Hauk \& Padberg, 2016; Qiu \& Benbasat, 2009). Intrusiveness is a major barrier to the adoption of smart products (Benlian et al., 2019; Hoffman \& Novak, 2015; Mani \& Chouk, 2017) and can influence other marketing variables like recommendations, acceptance (Van den Broeck, Zarouali, \& Poels, 2019), and continuance to usage (Benlian et al., 2019). However, little is known about its effect on usefulness.

As a consequence, previous research has examined how to mitigate intrusiveness, for example, through other smart characteristics (Benlian et al., 2019; Van den Broeck et al., 2019). Studies have found that interactivity of smart products can increase trust and, in turn, mitigate negative perceptions such as privacy invasion (Rijsdijk \& Hultink, 2003, 2009). Interactivity has been gaining attention from academics in recent years as the possibility of interaction anytime and anywhere has increased (Fan, Liu, Wang, \& Wang, 2017). However, no research has yet examined how the perceived interactivity of a smart product can mitigate the negative perceptions derived from its autonomy.

The present study has three aims. The first is to examine the effect of autonomy on perceived intrusiveness and usefulness by analyzing a non-linear relationship. Second, it investigates whether perceived interactivity can reduce the perceived intrusiveness of smart products, both directly and indirectly, by increasing trust in the service provider. The research also examines the effect of interactivity and intrusiveness on usefulness. Third, it aims to discover whether perceived interactivity can act as a moderator and reduce the effect of perceived autonomy on intrusiveness.

This research contributes to the marketing literature by providing empirical evidence not only of the direct effect of autonomy on usefulness, but also of its indirect effect through intrusiveness. The results suggest a non-linear effect of autonomy on usefulness and on intrusiveness. The research offers evidence of the negative effect of intrusiveness on perceived usefulness and highlights that autonomy is an important antecedent of intrusiveness. Additionally, this study contributes by examining how the benefits of the product's interactivity can mitigate the perceived intrusiveness of smart home assistants directly and indirectly. Furthermore, previous work has mainly examined interactivity in the online context. The present research provides an example of a new context (smart home voice assistants) in which interactivity is relevant, and it presents empirical evidence of the benefits to brand trust and the usefulness of the device. These results have implications for marketing managers and smart product developers.

\section{Conceptual Development}

\section{Intrusiveness}

Intrusiveness is defined as "the consumer's perception that the company abusively penetrates into his/her private life" (p. 843) (Boeck, Roy, Durif, \& Grégoire, 2011). It is related to the surveillance of the users and their daily lives. This surveillance includes the acquisition, usage, and storage of personal data (Plangger \& Montecchi, 2020) to monitor and control everything from screen time and hygiene habits to meal and travel schedules and other activities. Some devices are full of sensors and microphones that are envisioned as part of a surveillance web to chart families' domestic patterns so that marketing can be more easily targeted at them based on their interests (Holtrop, Wieringa, Gijsenberg, \& Verhoef, 2017). Surveillance has a negative connotation related to privacy costs and security risks due to some covert surveillance tactics (Albrechtslund, 2008). This intrusiveness is disturbing, irritating, and indiscreet (Krafft, Arden, \& Verhoef, 2017; Mani \& Chouk, 2017). Nowadays, consumers can connect and use their smart products anywhere and at any time, sometimes the devices collect information without the consumers' knowledge (Silaban, Hasudungan, Nadapdap, Situmeang, \& Situmeang, 2019). A well-known example is the case of a police murder investigation in the US that drew on information collected by a voice home assistant that was listening during the incident without the users being aware of it (Buhr, 2016).

Linked to surveillance is the concept of information privacy, which involves an individual's ability to control the use, release, collection, storage, and access to their personal data (Malhotra, Kim, \& Agarwal, 2004). When users perceive the smart device as being intrusive, they also perceive the probability of having a privacy breach (Benlian et al., 2019; Yang, Lee, \& Zo, 2017). Users become aware of the intrusiveness of this technology when they receive information about products or services without asking for it. They then realize that the smart device has activated without their explicit instruction and has inconspicuously listened to and collected information from the user and others in the vicinity for disclosure to service providers.

\section{Autonomy}

According to Rijsdijk and Hultink (2009, p. 26), autonomy "refers to the extent to which a product is able to operate in an independent and goal-directed way without interference of the user." An autonomous product does not need human intervention but instead takes over on its own, can show proactive and self-starting behavior (Benlian et al., 2019; Hoffman \& Novak, 2015), and can work together with human beings to liberate consumers of some unwanted chores (Cronin, 2010) or cognitive decisions (Broniarczyk \& Griffin, 2014). Autonomous products take over tasks, allowing the consumer to use the time and effort saved to participate in other activities.

Rijsdijk and Hultink (2003) proposed four different levels of autonomy: manual, bounded, supervised autonomy, and symbiosis. Bounded autonomy is when the product acts after the user has selected all the options for doing the activity. At the supervised autonomy level, the smart product can provide some advice about the activity. At the symbiosis level, the product communicates with the user to fulfill the proposed activity. The symbiosis level requires an integration of products in the house and sensors, which is known as a smart home where the smart assistant can control other smart domestic devices such as smart lights, smart fridges, smart washing machines, smart coffee makers, smart heating, and smart doors. Each of these other devices can also be autonomous. For example, a smart washing 
machine can decide the water, detergent, and the program depending on the clothes that the machine's sensors detect, and smart lights can change their intensity depending on the sunlight and even have the ability to switch themselves on/off.

\section{Interactivity}

Marketing researchers have paid attention to interactivity mainly in the online context. Interactivity exists when a person clicks on a machine and the machine does something (such as retrieving information or presenting content) in response to a person's request (Hoffman \& Novak, 1996).

The literature conceptualizes interactivity as a multidimensional construct (Cyr, Head, \& Ivanov, 2009; Lee, 2005; Wu \& $\mathrm{Wu}, 2006)$. Mollen and Wilson (2010) stated that perceived interactivity is an experiential phenomenon that occurs when a user interacts with a website or other computer-mediated communication entities. Perceived interactivity is "the degree to which the user perceives that the interaction or communication is two-way, controllable, and responsive to their actions." (p. 5). Several studies (Chattaraman, Kwon, Gilbert, \& Ross, 2019; Cyr et al., 2009; Horning, 2017; Liu \& Shrum, 2002; McMillan \& Hwang, 2002; Mollen \& Wilson, 2010; Song \& Zinkhan, 2008; Wu \& Wu, 2006; Yadav \& Varadarajan, 2005) have reached a degree of consensus on the core dimensions of perceived interactivity: perceived user control, two-way communication, and perceived responsiveness.

Previous research considers interactivity as part of the customers' experience with smart products, together with customer perceptions, such as perceived enjoyment and relative advantage (Roy, Balaji, Sadeque, Nguyen, \& Melewar, 2017). During the last decade, there has been an expansion of embodied conversational agents that are capable of establishing conversations and being interactive, both on screens (such as Apple's Siri and Google's Ok) and as physical devices (such as Amazon's Alexa and Google's Echo speakers). The key is the existence of a process involving continuous exchange of messages in a two-way communication flow (Hood, Shanahan, Hopkins, \& Lindsey, 2015). Interactivity is one of the main characteristics of smart products since it is an element of the user interface (Hoffman \& Novak, 2015). However, while previous research on smart speakers has focused on the influence of some characteristics on their adoption or on user satisfaction (Mani \& Chouk, 2019; Rijsdijk \& Hultink, 2009), previous studies have not included interactivity among these characteristics. Moreover, research has yet to examine the assistants' ability to reduce a customer's negative perceptions about the product, or the assistants' relationship with other variables examined in the previous literature in other contexts, such as trust, attitude, or loyalty.

Table 1 provides some examples of the main variables of this study: autonomy, intrusiveness, and autonomy.

\section{Perceived Usefulness}

The Technology Acceptance Model (TAM) and its modified versions consider perceived usefulness as the main construct.
Perceived usefulness is "the degree to which a person believes that using a particular system would enhance his or her job performance" (Davis, 1989, p. 320). Research about smart products defines perceived usefulness as "the extent to which a consumer believes that using them increases his or her personal efficiency, such as being more organized and more productive" (Chuah et al., 2016 p. 278). Connected objects offer a multitude of new service systems and assemblages, functions, and information, allowing better time management for users (Hoffman \& Novak, 2018; Novak \& Hoffman, 2019; Touzani, Charfi, Boistel, \& Niort, 2018). Perceived usefulness is a main determinant of smart product adoption (Adapa, Nah, Hall, Siau, \& Smith, 2018; Chuah et al., 2016; Ghazal, Akmal, Iyanna, \& Ghoudi, 2016) and can reduce consumers' resistance (Mani \& Chouk, 2017). Research in the context of voice assistants has recently examined perceived usefulness as an antecedent of a customer's attitude, adoption, or satisfaction to explain the use of these types of assistant (Fernandes \& Oliveira, 2020; McLean \& Osei-Frimpong, 2019; Moriuchi, 2019).

\section{Model and Hypotheses}

\section{Autonomy}

Based on the definition of Hoffman and Novak (2015), smart products are intrusive because they have the ability to perform actions autonomously and without the permission of the consumer. An important cause of intrusiveness is the potential for unintentional voice activation of products that listen continuously to the environment so that they can react to the consumer's needs. Previous research has shown that autonomy of smart home assistants results in a potentially high level of intrusiveness (Benlian et al., 2019; Mani \& Chouk, 2019).

An autonomous product that automatically reacts to voices can create situations in which a consumer does not know whether the smart home assistant is on or off. As a result, the product starts to collect information from the environment about the consumer's behavior, and the device can share this information with third-party service providers (Wueest, 2017). Benlian et al. (2019) suggested that the unintentional activation of the technology, and the consumer's lack of awareness of whether the smart home assistant is on or off, are the most significant causes of privacy invasion in practice (Mani \& Chouk, 2019) and they increase the consumer's perception that service providers are encroaching upon private lives. The fear of privacy violations and the concerns about data security drive this increased perception of risk (Keh \& Pang, 2010). It seems, therefore, that, at low levels of autonomy, the product is unable to act by itself and start listening without the user's interaction, and that, as autonomy increases, the benefits can outweigh the risks until to the point that increasing autonomy leads to a loss of control, thereby increasing the perception of intrusiveness.

H1. Autonomy will have a U-shaped effect on intrusiveness.

However, autonomy has some benefits for the consumer. Autonomous products take over tasks, allowing the consumer 
Table 1

Constructs definitions.

\begin{tabular}{lll}
\hline Construct & Definition & Example \\
\hline Intrusiveness & $\begin{array}{l}\text { Intrusiveness is related to the surveillance of the user and his/her } \\
\text { daily life. }\end{array}$ & $\begin{array}{l}\text { The user has a conversation by phone with a friend about going on a holiday } \\
\text { cruise, and, when s/he activates the smart home speaker, it offers her/him } \\
\text { information about a cruise holiday. }\end{array}$ \\
Autonomy & $\begin{array}{l}\text { The ability of a machine to act on its own, perceive its } \\
\text { environment, and take actions to maximize its chances of success } \\
\text { in a defined task. }\end{array}$ & $\begin{array}{l}\text { The users sets } 7: 30 \text { as the time to wake up. The assistant wakes up the user with a } \\
\text { assistant automatically downloads new songs to the user's smartphone each } \\
\text { month, depending on the songs that the user currently has on her/his smartphone } \\
\text { or on his/her preferences. }\end{array}$
\end{tabular}

Home entertainment systems, such as smart TVs connected with lighting in the home, can improve the living atmosphere by automatically adjusting the lighting to the colors of the TV screen.

Interactivity The degree to which the user perceives that the interaction or High interactivity:

communication is two way, controllable, and responsive to their User: "activation word," can you tell me the best way to get to work?

actions.

HVA: Yes, of course. Today is Friday and the usual way to get to work is through the city center. However, some big retailers are beginning some promotions and sales today, so the city center has a strong probability to be congested. Would you like me to offer other options?

User: Yes, thank you.

HVA: Here are all the alternatives. What do you want me to include in your GPS? User: "activation word," I want to take the fastest option.

$H V A$ : The fastest option is to take the highway.

(Suddenly, the user realizes she wants to have a coffee to take away from a cafeteria in the city center:)

User: "activation word," I would like a coffee to take away at Paco's on the way to work.

HVA: That's a good idea. Would you like me to offer you options to get to work by passing by Paco's?

User: Yes, thank you.

User: "activation word," what are blackheads?

HVA: According to the website healthline.com: "They are small bumps that appear on your skin due to clogged hair follicles." Would you like to know how to get rid of them?

User: "activation word," yes, please.

HVA: According to the website healthline.com, there are natural remedies or you can use some specific products. I can give you more details about each of them. What do you prefer?

User: "activation word," I prefer buying specific products.

HVA: Great. Here is a list of the most recommended products that you can buy on Amazon to get rid of blackheads.

Low interactivity:

User: "activation word," can you tell me the best way to get to work?

HVA: Yes, of course. Today is Friday and the usual way to get to work is through the city center.

(Suddenly, the user realizes she wants to have a coffee to take away from a cafeteria in the city center:)

User: "activation word," I would like a coffee to take away at Paco's.

HVA: That's a good idea.

User: "activation word," tell me how to get to Paco's and then to get to work.

User: "activation word," what are blackheads?

HVA: According to the website healthline.com: "They are small bumps that appear on your skin due to clogged hair follicles."

User: "activation word" how do I get rid of them?

HVA: According to the website healthline.com, there are natural remedies or you can use some specific products.

User: "activation word," tell me the products that I can buy to get rid of blackheads.

HVA: Here is a list of the recommended products to get rid of blackheads that you can buy on Amazon 
to save time and effort to participate in other activities. Consumers may, therefore, perceive autonomous smart products as devices that increase their comfort and well-being, increase their task fulfillment efficiency and effectiveness, or liberate them from unwanted chores (Cronin, 2010; Leung, Paolacci, \& Puntoni, 2018). In general, previous research has found a positive effect between autonomy and relative advantage (Rijsdijk \& Hultink, 2003). Autonomy involves private information collection that can provide users with personalized messages (Zeng, Ye, Li, \& Yang, 2021) and helps the product to be more efficient in performing the requested tasks, thereby increasing its usefulness. As a consequence, the autonomy of smart products has advantages up to the point when autonomy may increase the loss of control over the product and create discomfort. This can lead to users having to reconfigure the product, reducing its perceived advantages (Rijsdijk \& Hultink, 2003, 2009). Thus, we propose:

H2. Autonomy will have an inverted U-shaped effect on perceived usefulness.

\section{Intrusiveness}

Intrusiveness in marketing is considered to have a negative impact on consumer behavior. Unsolicited targeted ads or unprompted recommendations for third-parties, as well as unintentional voice activation, constitute the most severe concerns with respect to privacy invasion in households (Benlian et al., 2019). These lead to users feeling that they lose control over the information that is disclosed (Dinev, $\mathrm{Xu}$, Smith, \& Hart, 2013; Klumpe, Koch, \& Benlian, 2018), which can even breed mistrust (Mosteller \& Poddar, 2017), thus making them less likely to use the product (Ayyagari, Grover, \& Purvis, 2011; Xu \& Gupta, 2009). Some research has found that intrusiveness is a barrier to consumers' adoption of new technologies (Boeck et al., 2011; Mani \& Chouk, 2017) or to the use of geo-location services (Hérault \& Belvaux, 2014). Furthermore, it triggers individual negative emotional reactions (Edwards, Li, \& Lee, 2002). Benlian et al. (2019) recently suggested that smart home assistants generate stress in the home and conflict between family members because the technology invades privacy (Hauk \& Padberg, 2016; Qiu \& Benbasat, 2009). Moreover, this intrusiveness reduces the user's acceptance of the message provided by the assistant (Van den Broeck et al., 2019), which can reduce perceived usefulness. Previous research has suggested that the perceived benefits of smart speakers decrease when the device is activated unintentionally, because it disturbs the convenience of the device (Benlian et al., 2019).

H3. Intrusiveness will have a negative effect on perceived usefulness.

\section{Brand Trust}

Trust in service providers is the consumer's willingness to rely on them (Morgan \& Hunt, 1994). It is related to the consumer's beliefs and expectations about whether the smart product's brand is honest, reliable, and dependable (Carvalho \& Fernandes, 2018; Pavlou, 2003; Yang et al., 2017). The perception that the brand behaves fairly, accountably, and responsibly is essential for trust development (Singh, Iglesias, \& Batista-Foguet, 2012). Consumers trust in vendors when they think that the vendors will not behave opportunistically (Gefen, Karahanna, \& Straub, 2003).

In the technology adoption field, previous research has shown that trust is a key instrument for the acceptance of technology (Gefen, 2000). In the smart home industry, users fear data collection from big information technology companies (Yang et al., 2017), and trust has a positive effect on the attitudes of users of smart home devices (Luor, Lu, Yu, \& Lu, 2015). Furthermore, brand trust can make users perceive that the surveillance of smart products is less harmful and intrusive, since they think that the brand is honest and benevolent (Plangger \& Montecchi, 2020). So, we propose:

H4. Trust will have a negative effect on intrusiveness.

\section{Interactivity}

As previously defined, interactivity refers to the extent to which users perceive that the communication with the home voice assistant is reciprocal, takes place instantaneously, and is controllable (Liu, 2003). Technological products are interactive if there is a bidirectional flow that the user can control to a certain extent and within a time frame. Home voice assistants can establish this communication flow and allow users to control for their interactions. Interactivity with the smart product can lead users to a perception of being co-responsible for the product's "acts" and their consequences, creating a collaborative experience (To et al., 2018). Furthermore, using voice to interact with consumers favors the creation of a character for these assistants and leads to more engaging interactions (Kidd, 2008). Interactivity with smart products helps customers co-create their experience with the product, influencing their relationship with the company and the brand (Barwitz \& Maas, 2018). Therefore, if the speaker allows bidirectional communication, it is able to understand and answer a consumer's queries, and the consumer is able to control the product as well as their ability to voluntarily interact with it or not; as a result, the consumer will behave more actively and feel more confidence in dominating the interaction and handling the situation (Liu \& Shrum, 2002; Roy et al., 2017; Verhoef et al., 2017). The better the interaction and the communication, the more the product provides information about how it will perform the task, which will reduce the perceived intrusiveness of the product. Therefore, we propose the following hypothesis:

H5. Perceived interactivity will have a negative effect on intrusiveness.

Greater interactivity empowers consumers as it facilitates their communication with products and brands directly, regardless of distance or time (Deighton \& Kornfeld, 2009). This interactivity can lead to trust in the service provider and greater customer loyalty in the e-commerce context (Cyr et al., 
2009; Lee, 2005). Research has conceptualized trust as an important component of credibility (McCroskey \& Teven, 1999). Consumers can gather the information they need to make decisions and reduce uncertainty through the interaction with smart products (Koo \& Choi, 2010; Sun, Fang, \& Hwang, 2019). A high level of interactivity enables the smart product to share information and knowledge, providing consumers with high-quality information to make better decisions (Bayus, 2013; Chan, Li, \& Zhu, 2015), which, in turn, makes the product seem more trustable (Wang, Chih, \& Hsu, 2020). In relation to social commerce platforms, Liang, Ho, Li, and Turban (2011) demonstrated that consumers can receive information support through interaction, which can make them feel safe, increase their trust in these platforms, and lessen their concern about privacy issues. As a consequence, perceived interactivity can reduce intrusiveness not only directly but also indirectly through an increase in trust. Accordingly, our next hypothesis is:

H6. Perceived interactivity will have an indirect effect on intrusiveness mediated by trust.

In the context of online shopping sites, previous research has shown that interactivity with virtual assistants (also known as avatars) can increase patronage intentions (Etemad-Sajadi, 2016) and that it positively influences other TAM constructs, such as self-efficacy, perceived ease of use, and perceived usefulness (Abdullah, Jayaraman, Shariff, Bahari, \& Nor, 2017; Chattaraman et al., 2019; Coursaris \& Sung, 2012; Lee, Fiore, \& Kim, 2006; Thellman, Silvervarg, Gulz, \& Ziemke, 2016; Veletsianos \& Navarrete, 2012). The level of interactivity of the virtual assistant is useful if it helps users make decisions about their purchases or life. Interactivity involves two-way communication and responsiveness. Usefulness may increase when the product offers rich, valuable, and high-quality two-way communication. When two parties communicate, a fast response time contributes to the continuity of communication (Gao, Rau, \& Salvendy, 2010), and, therefore, it increases the perceived usefulness of the product.

H7. Perceived interactivity will have a positive effect on perceived usefulness.

\section{Moderating Effect of Interactivity}

Little is known about how to reduce the negative effects of autonomy on intrusiveness or privacy risk. Recent research has examined whether the anthropomorphic design features reduce smart home assistants' intrusiveness and their negative effects on privacy (Benlian et al., 2019), and other researchers have suggested that human-like features increase trust (Aggarwal \& McGill, 2007; Landwehr, McGill, \& Herrmann, 2011; Waytz, Heafner, \& Epley, 2014). However, an important characteristic of the product that can also increase trust is perceived interactivity. As discussed above, perceived interactivity involves an effective two-way communication, providing useful answers in an efficient time frame that can also be interpreted as human-like aspects. Interactivity increases product knowledge (Yim \& Park, 2019), which can help users

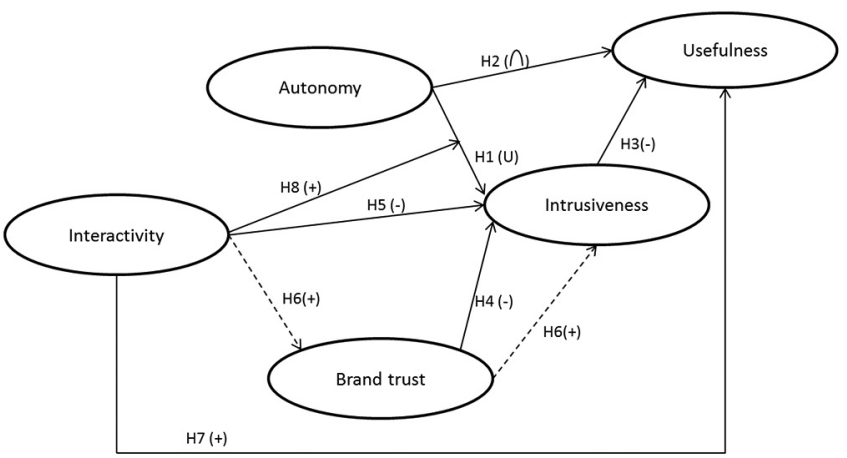

$\begin{array}{ll}- & \text { Direct effect } \\ -\cdots-- & \text { Indirect effect }\end{array}$

Fig. 1. Model proposed.

obtain information about the product and increase their confidence in it (Deighton \& Kornfeld, 2009). The level of interactivity of the product can reduce the negative consequences of autonomy. Baber (1996) illustrated this aspect by using a washing machine as an example. He suggested that the highest level of autonomy would involve the machine setting the program, starting itself, and giving advice. At this point, the user starts an interaction with the product and a symbiosis would occur. To provide advantages for the consumer, the ongoing communication between the user and the product would go in the same direction in order to fulfill a common goal. Therefore, as that communication is bidirectional, it is helpful, fast, and controlled by the user, and hence it will reduce the negative effect of autonomy on intrusiveness. Accordingly, we propose the following hypothesis:

H8. Perceived interactivity will have a negative moderating effect on the relationship between autonomy and intrusiveness.

Fig. 1 shows the model to be tested.

\section{Methodology}

To test the hypotheses, we collected data using a survey questionnaire administered on the Mechanical Turk website. Initially, we obtained 651 responses, but we eliminated four that used more than one smart home voice assistant, 15 that answered all the questions with the same value or following a pattern, and 25 that incorrectly responded to the two filter questions that controlled for the respondent's concentration. This yielded a total of 607 valid responses. ${ }^{1}$ There were $51.5 \%$ male respondents, and the age of participants was, on average, 34.5 years old. With regard to educational attainment, $16.2 \%$ of the participants possessed a Master's or PhD degree, $40.1 \%$ of the participants held a university degree as their highest qualification, and $35.1 \%$ had a secondary school education only. In relation to the brand of the device, $56.2 \%$ used Alexa, 29.5\% Google Home, 7.7\% Cortana, 5.6\% Home Pod (Apple),

\footnotetext{
${ }^{1}$ A common concern in using Mechanical Turk is that not every survey-taker is unique. We addressed this concern in two ways in our data processing. First, we set up Mechanical Turk so that each respondent was asked to complete a single survey; second, we checked that no responses had identical Mechanical Turk IDs.
} 
and $1 \%$ reported that they used other brands. The mean duration that respondents had been using the devices was 14.23 months.

The measurement of the variables follows constructs used in previous research (for the instrument, see the Appendix). All constructs are reflective and were measured using a seven-point Likert scale, from $1=$ "completely disagree" to $7=$ "completely agree." Autonomy is a reflective construct containing four items (Rijsdijk, Hultink, \& Diamantopoulos, 2007) and intrusiveness has four items (Mani \& Chouk, 2017). Interactivity is a second-order reflective construct that contains three reflective components: two-way communication, responsiveness, and perceived control. Two-way communication has five items and responsiveness six items adapted from Song and Zinkhan (2008). Perceived control has eight items adapted from Lee, Moon, Kim, and Mun (2015) and Liu (2003). Trust is a reflective construct that consists of four items (DelgadoBallester, 2004; Hsu et al., 2014; Yang et al., 2017). Perceived usefulness is a reflective construct with five items based on previous research (Hsu \& Lin, 2016; Saeed \& AbdinnourHelm, 2008).

\section{Results}

\section{Measurement Model}

First, the authors carried out an exploratory factor analysis using SPSS to check the unidimensionality of the reflective constructs. A factorial analysis with varimax rotation confirmed nine dimensions. Then, the next analysis was a confirmatory factor analysis carried out using SmartPLS 3.0 software.

Common method variance could pose a serious problem. Therefore, the authors conducted a Harmon's one-factor test. The results show that a single factor explained $21.4 \%$ of the variance; when all five factors in the model are taken into account, the variance explained increases to $74.4 \%$. Thus, there is no indication of any problem with common method variance.

The results proposed to eliminate some items-one item each of communication, responsiveness, and perceived control - to obtain the quality criteria (see Table 2). After that, all factor loadings of the constructs exceeded the minimum acceptable value of 0.7 (Carmines \& Zeller, 1979). Cronbach's alpha values and the composite reliability index for all constructs exceeded the minimum acceptable value of 0.7 (Hair, Ringle, \& Sarstedt, 2011; Nunnally, 1978), confirming internal consistency. To evaluate discriminant validity, we obtained the average variance extracted (AVE); this exceeded the threshold of 0.6 (Hair et al., 2011). Table 3 shows the discriminant validity results according to the criterion of Fornell and Larcker (1981) and the HTMT (heterotraitmonotrait) ratio proposed by Henseler, Ringle, and Sarstedt (2015). All values were below 0.85, indicating discriminant validity among the constructs. The analysis uses consistent partial least squares (PLSc) algorithm to obtain more robust results.
Table 2

Measurement model reflective constructs.

\begin{tabular}{|c|c|c|c|c|c|}
\hline & $\begin{array}{l}\text { Factor } \\
\text { loading }\end{array}$ & $\begin{array}{l}\text { Cronbach's } \\
\text { alpha }\end{array}$ & Rho_A & $\begin{array}{l}\text { Composite } \\
\text { reliability }\end{array}$ & AVE \\
\hline AUTONOMY & & 0.924 & 0.924 & 0.924 & 0.812 \\
\hline AUT_1 & 0.898 & & & & \\
\hline AUT_2 & 0.879 & & & & \\
\hline AUT_3 & 0.911 & & & & \\
\hline AUT_4 & 0.916 & & & & \\
\hline INTERACTIVITY & & 0.739 & 0.747 & 0.851 & 0.656 \\
\hline COMMUNICATION & 0.768 & 0.869 & 0.860 & 0.868 & 0.622 \\
\hline COM_1 & 0.901 & & & & \\
\hline COM_2 & 0.875 & & & & \\
\hline COM_3 & 0.844 & & & & \\
\hline COM_4 ® & Eliminated & & & & \\
\hline COM_5 & 0.748 & & & & \\
\hline RESPONSIVENESS & 0.822 & 0.913 & 0.913 & 0.913 & 0.677 \\
\hline RESP_1 & 0.853 & & & & \\
\hline RESP_2 & 0.899 & & & & \\
\hline RESP_3 & 0.849 & & & & \\
\hline RESP_4 & 0.864 & & & & \\
\hline RESP_5 ® & Eliminated & & & & \\
\hline RESP_6 & 0.840 & & & & \\
\hline $\begin{array}{r}\text { PERCEIVED } \\
\text { CONTROL }\end{array}$ & 0.838 & 0.929 & 0.931 & 0.929 & 0.653 \\
\hline PC_1 & Eliminated & & & & \\
\hline PC_2 & 0.739 & & & & \\
\hline PC_3 & 0.770 & & & & \\
\hline PC_4 & 0.835 & & & & \\
\hline PC_5 & 0.827 & 0.933 & 0.934 & 0.933 & 0.777 \\
\hline PC_6 & 0.816 & & & & \\
\hline PC_7 & 0.870 & & & & \\
\hline PC_8 & 0.792 & & & & \\
\hline INTRUSIVENESS & & 0.933 & 0.935 & 0.933 & 0.833 \\
\hline INT_1 & 0.926 & & & & \\
\hline INT_2 & 0.925 & & & & \\
\hline INT_3 & 0.814 & & & & \\
\hline INT_4 & 0.854 & & & & \\
\hline TRUST & & 0.923 & 0.924 & 0.923 & 0.812 \\
\hline TR_1 & 0.840 & & & & \\
\hline TR_2 & 0.832 & & & & \\
\hline TR_3 & 0.881 & & & & \\
\hline TR_4 & 0.907 & & & & \\
\hline USEFULNESS & & 0.935 & 0.936 & 0.935 & 0.743 \\
\hline USEF_1 & 0.866 & & & & \\
\hline USEF_2 & 0.853 & & & & \\
\hline USEF_3 & 0.855 & & & & \\
\hline USEF_4 & 0.814 & & & & \\
\hline USEF_5 & 0.917 & & & & \\
\hline
\end{tabular}

Table 3

Discriminant validity.

\begin{tabular}{llllll}
\hline & Trust & Autonomy & Interactivity & Intrusiveness & Usefulness \\
\hline Trust & $\mathbf{0 . 8 6 6}$ & 0.297 & 0.748 & 0.359 & 0.691 \\
Autonomy & 0.302 & $\mathbf{0 . 8 6 8}$ & 0.283 & 0.341 & 0.222 \\
Interactivity & 0.697 & 0.267 & $\mathbf{0 . 8 1 0}$ & 0.384 & 0.834 \\
Intrusiveness & -0.362 & 0.334 & -0.384 & $\mathbf{0 . 8 8 1}$ & 0.370 \\
Usefulness & 0.691 & 0.227 & 0.733 & 0.372 & $\mathbf{0 . 8 6 2}$ \\
\hline
\end{tabular}

Note: Values (in bold) on the diagonal are square roots of the AVE. Values below the diagonal are correlations between variables. Values above the diagonal are values of the heterotrait-monotrait ratio (HTMT). 


\section{Structural Results}

Table 4 shows the structural results of the model. To test predictive relevance, we used SmartPLS 3.0 M3 software (www.smartpls.de), which provides the $\mathrm{Q}^{2}$ value recommended by Stone (1974) and Geisser (1974). Our models show positive $\mathrm{Q}^{2}$ values for the main dependent variables.

The results show that there is a significant quadratic effect of autonomy on intrusiveness. However, Fig. 2 shows that the effect is only positive and that there is no U-shaped effect, so H1 is not supported. Fig. 3 shows that the impact of autonomy on usefulness has a U-shaped effect, so $\mathrm{H} 2$ is not supported. The results show that intrusiveness has a negative effect on perceived usefulness, supporting $\mathrm{H} 3$, and that trust has a negative and significant effect on intrusiveness, supporting $\mathrm{H} 4$. Interactivity has a negative and significant effect on intrusiveness, so H5 is supported, and a direct and positive effect on usefulness, supporting H7. Examining the mediating effect of trust (see Table 5), the results show that the indirect path of interactivity-trust-intrusiveness is significant, confirming a partial mediation and supporting H6. Additionally, the indirect paths of autonomy-intrusiveness-usefulness and interactivityintrusiveness-usefulness are also significant, showing a partial mediation of intrusiveness in the relationship between autonomy and usefulness and between interactivity and usefulness. The results show that the moderating effect of interactivity is negative and significant, so $\mathrm{H} 8$ is supported. Fig. 4 shows the moderating effect of interactivity on autonomy. When interactivity is high, a slightly U-shaped effect of autonomy on intrusiveness is perceived. When interactivity is high, the effect of the level of autonomy on intrusiveness is lower than when interactivity is low.

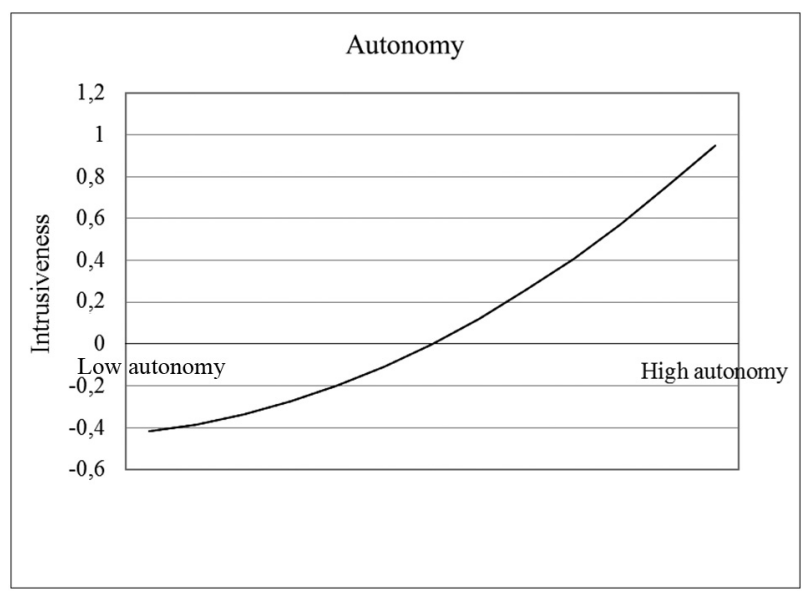

Fig. 2. Quadratic effect of autonomy on intrusiveness.

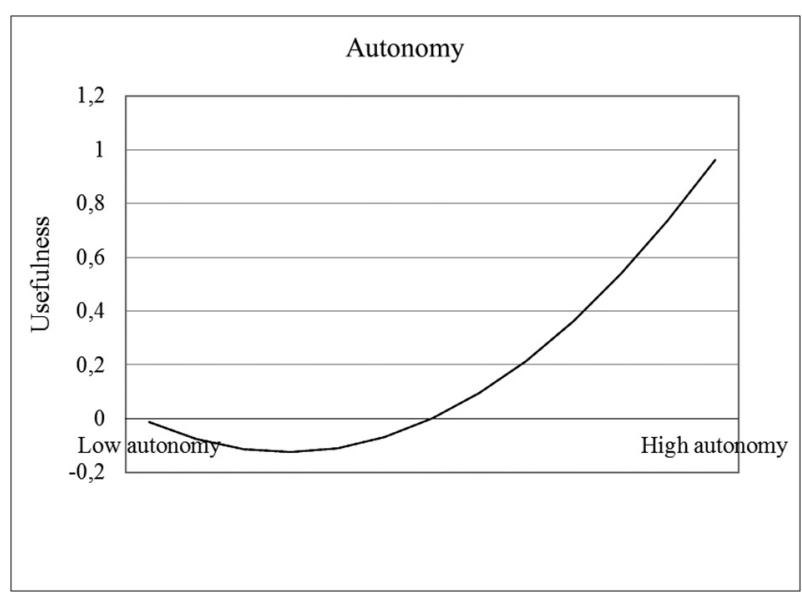

Fig. 3. Quadratic effect of autonomy on usefulness.

Table 4

Structural results.

\begin{tabular}{|c|c|c|c|c|c|c|}
\hline & Original sample $(\mathrm{O})$ & $\begin{array}{l}\text { T statistics } \\
(\mid \mathrm{O} / \mathrm{STDEVI})\end{array}$ & $\mathrm{R}^{2} / \mathrm{Q}^{2}$ & Original sample $(\mathrm{O})$ & $\begin{array}{l}\text { T statistics } \\
(\mid \mathrm{O} / \mathrm{STDEV} \mathrm{I})\end{array}$ & $\mathrm{R}^{2} / \mathrm{Q}^{2}$ \\
\hline autonomy ${ }^{2} \rightarrow$ useful & 0.211 & 5.442 & & 0.211 & 5.442 & \\
\hline autonomy $\rightarrow$ useful & 0.325 & 7.960 & & 0.325 & 7.960 & \\
\hline intrusiveness $\rightarrow$ useful & $-0.087^{* *}$ & 1.644 & & $-0,087 * *$ & 1,672 & \\
\hline Autonomy ${ }^{2} \rightarrow$ intrusiveness & $0.118 * *$ & 2.234 & & $0,210^{* *}$ & 2,243 & \\
\hline autonomy $\rightarrow$ intrusiveness & $0.456 * * *$ & 12.643 & & $0,514 * * *$ & 7,547 & \\
\hline trust $\rightarrow$ intrusiveness & $-0.291 * * *$ & 4.177 & & $-0,281 * * *$ & 3,621 & \\
\hline interactivity*autonomy $\rightarrow$ intrusiveness & & & & $-0,143^{*}$ & 1,436 & \\
\hline \multicolumn{7}{|l|}{ Control variables } \\
\hline education $\rightarrow$ intrusiveness & $0.182 * * *$ & 5.353 & & $0,164 * * *$ & 4,205 & \\
\hline gender $\rightarrow$ intrusiveness & $-0.049 *$ & 1.356 & & $-0,044$ & 1,191 & \\
\hline age $\rightarrow$ intrusiveness & 0.022 & 0.653 & & 0,037 & 1,021 & \\
\hline
\end{tabular}

*** Significant at the $1 \%$ level. ** Significant at the $5 \%$ level. 
Table 5

Indirect effects.

\begin{tabular}{llll}
\hline & $\begin{array}{l}\text { Original } \\
\text { sample }(\mathrm{O})\end{array}$ & $\begin{array}{l}\text { T statistics } \\
(\mid \mathrm{O} / \mathrm{STDEVI})\end{array}$ & P values \\
\hline interactivity $\rightarrow$ trust $\rightarrow$ intrusiveness & $-0,210$ & 3,582 & $\mathbf{0 , 0 0 0}$ \\
autonomy $\rightarrow$ intrusiveness $\rightarrow$ useful & $-0,045$ & 1,672 & $\mathbf{0 , 0 4 7}$ \\
interactivity $\rightarrow$ intrusiveness $\rightarrow$ useful & 0,031 & 1,672 & $\mathbf{0 , 0 4 7}$ \\
\hline
\end{tabular}

*** Significant at the $1 \%$ level. ** Significant at the $5 \%$ level.

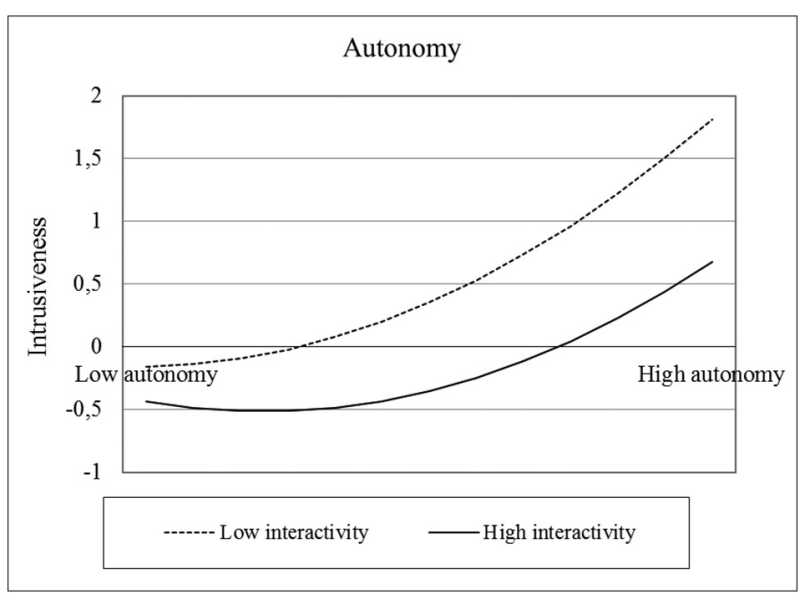

Fig. 4. Moderating effect of interactivity.

\section{Discussion}

This research aimed, first, to analyze the non-linear effect of the level of autonomy of smart products on perceived intrusiveness and usefulness; second, to examine how perceived interactivity of the product can reduce the negative effect of autonomy on intrusiveness; and, third, to discover whether perceived interactivity can reduce intrusiveness through an increase in trust. This paper has examined not only a direct effect of interactivity on intrusiveness but also a moderating effect on the relationship between autonomy and intrusiveness and an indirect effect on intrusiveness through trust.

Contrary to our expectations, our findings suggest that autonomy has a U-shaped effect on perceived usefulness. Previous research has found evidence only of a linear relationship (Rijsdijk \& Hultink, 2003, 2009). Our findings show that, although there is a U-shaped effect, the main values of autonomy show a positive effect, which is consistent with previous research. Only for a very low level of perceived autonomy is the relationship between autonomy and perceived usefulness negative. Furthermore, the results show that the effect of autonomy on usefulness is not only direct, as previously found (Rijsdijk \& Hultink, 2003, 2009), but that it also impacts on usefulness in an indirect way through intrusiveness. This result confirms previous research that suggests that intrusiveness can reduce the convenience of the device (Benlian et al., 2019). Previous research has found that intrusiveness reduces the consumer's acceptance of the message or information provided by the chatbot (Van den Broeck et al., 2019), and, therefore, the message or information's perceived usefulness. Thus, our research offers new empirical support for the negative consequences of intrusiveness, showing that they are motivated, at least in part, by autonomy.

The results show that autonomy has a non-linear U-shaped effect on intrusiveness, but there is no evidence that increasing autonomy until a certain point may have a negative effect on intrusiveness. Therefore, the results have only found a positive effect of autonomy on intrusiveness confirming previous research (Benlian et al., 2019; Hoffman \& Novak, 2018; Mani \& Chouk, 2019). We expected the smart product's autonomy not to have a strong positive effect on intrusiveness when its levels are low, as the advantages of that autonomy on well-being may eliminate that effect. Low levels of autonomy do not require the collection of as much information about the environment or the user, so we expected low levels of intrusiveness until a point at which the smart product needs more surveillance and gathers more information to operate more autonomously and perform its task efficiently. A possible explanation for the unexpected result is that the relationship between autonomy and intrusiveness may vary depending on the use of the home speaker. Home speakers have different functionalities, from searching for information on the Internet, playing music, making phone calls, and managing lists to reading out recipe instructions, to controlling other devices in the home, such as smart door locks and smart lights. The level of autonomy and its effect on intrusiveness may vary depending on the type of use, because the device needs to collect different types of private information depending on the task it is requested to perform.

The findings suggest that perceived interactivity is an important smart characteristic that can increase perceived usefulness, as previous research on different contexts has suggested (Chattaraman et al., 2019; Coursaris \& Sung, 2012; Lee et al., 2006). Our findings show that the higher the interactivity, the lower the perceived intrusiveness of the product. No previous research has focused on how this smart product characteristic can mitigate this effect, although evidence has been found of the benefits of interactivity on other aspects, such as trust, satisfaction, repurchase intention, or repatronage intention (Cho, 2004; Cyr et al., 2009; Kim, Spielmann, \& McMillan, 2012; Lin, 2007). Previous research has suggested that interactivity increases trust in service providers (Dennis, Merrilees, Jayawardhena, \& Wright, 2009; Merrilees \& Fry, 2002). Intrusiveness involves a lack of trust in the service provider or brand (Benlian et al., 2019; Wueest, 2017; Yang et al., 2017), so trust is an important condition to reduce privacy risk or intrusiveness. Our results confirm previous research that has found an indirect path in another context, namely, social commerce platforms (Liang et al., 2011). These findings contribute by providing more evidence of the indirect effect of interactivity through trust, but in this case to reduce intrusiveness. Our results show that interactivity influences usefulness, both directly with a strong positive impact and indirectly by reducing the negative impact of intrusiveness. Therefore, interactivity is an important smart 
characteristic that managers should take into account due to its positive consequences.

Finally, this research presents evidence of the moderating effect of interactivity on the relationship between autonomy and intrusiveness. Little is known about this effect as no previous research has focused on it. However, as Benlian et al. (2019) proposed in relation to anthropomorphic characteristics, the inclusion of some human-like characteristics can reduce the negative effect of privacy risk and privacy invasion by autonomous products. Interactivity involves efficient and useful two-way communication that also has human-like properties, and it allows users to exert a greater control over the product. We have found evidence that all these aspects together mitigate the perceived intrusiveness of very autonomous products.

This study makes three main contributions to marketing research. Although the negative aspects of smart products are always linked to intrusiveness and privacy risk, there has been little research on how to mitigate that negative perception, with some exceptions (Benlian et al., 2019). To focus on that variable is important as it is one of the main barriers to adoption of this type of product. The first contribution of our findings is the evidence of how the smart product characteristic of perceived interactivity can reduce perceived intrusiveness. Our results provide empirical evidence of the importance of perceived interactivity for that purpose, as this characteristic reduces perceived intrusiveness not only in a direct way, but also indirectly through trust in the provider. Furthermore, interactivity reduces not only the perceived intrusiveness of the product, but also the negative consequences of autonomy in terms of intrusiveness.

Second, previous research has examined the possibility of non-linear effects of autonomy on perceived advantages or on adoption intention, but the studies have always found a linear relationship between autonomy and intrusiveness (Mani \& Chouk, 2017; Rijsdijk \& Hultink, 2009). Our results provide evidence of a non-linear effect of autonomy on intrusiveness, with this effect being stronger for higher levels of autonomy. However, when this effect interacts with other variables such as interactivity, autonomy shows a U-shaped relationship for those consumers who perceive high interactivity.

Finally, our research presents new evidence of the relationship between autonomy and usefulness. Our results show a non-linear effect between these variables and that there is not only a direct effect of autonomy on usefulness, but also an indirect effect through intrusiveness. Previous research has mainly examined direct effects (Rijsdijk \& Hultink, 2003, 2009), whereas the indirect paths have been less investigated.

Our findings have some practical implications for managers and product development managers to reduce intrusiveness. First, product development managers should take into account the relationship between autonomy and intrusiveness. Consumers are still reluctant to adopt products with high levels of autonomy. Managers should consider autonomy seriously in product development, as this smart product characteristic increases the level of perceived intrusiveness of the product. However, according to our results, this effect can be mitigated through the level of interactivity. Therefore, managers should focus not only on developing autonomous products but also on ensuring that these products have a high level of perceived interactivity. The results show that improving and increasing the level of interactivity have positive effects, not only reducing intrusiveness but also increasing the perceived usefulness of the voice assistant. This is important because perceived usefulness is a main driver for the long-term use of smart voice assistants (McLean \& Osei-Frimpong, 2019). Therefore, autonomous products should also show a high level of two-way communication with consumers and provide quick and helpful answers to consumers' queries. Product developers should consider providing more information about the process and the steps that the autonomous product will take so users may feel greater control. Increasing the level of interactivity provides that advantage; in addition, the more interactive the home speaker, the lower the perception of intrusiveness due to increased generation of trust in the provider. This latter aspect is also relevant for managers due to the negative and controversial reports about home speakers. The perception of the intrusiveness of this type of product is increasing among consumers, and, at the same time, brand trust has decreased. Increasing the level of interactivity of the product can help to raise brand trust, which would enable a reduction of perceived intrusiveness.

This research also has limitations that allow us to propose some lines for future research. In this study, perceived interactivity is a second-order construct with three components. However, it would be interesting to examine whether the effect of each component is the same or if there are some interactive components that are more important in reducing intrusiveness. Perceived control, for example, can be one of the most important aspects to consider. In a similar way, future research can also examine the type of relationships of each component of interactivity. In this research, we have examined a direct, an indirect, and a moderating effect of interactivity, but what type of effect will each component show? Additionally, this study has focused on one type of product: smart home speakers. However, future research can replicate the study with other smart products because other products might yield different results. Additionally, future research can examine these relationships in a different country as consumers from different countries may value the level of autonomy in different ways due to cultural effects. The users of Mechanical Turk are mainly young and more innovative, so future research can use a wider sample. The research has focused on just one smart characteristic, interactivity, but others, such as human-like interaction or the level of personalization, might also help to reduce perceived intrusiveness. Finally, future research could focus on a more exhaustive analysis of the tradeoff between autonomy, intrusiveness, and usefulness by using other research techniques such as conjoint analysis. This technique can provide an overview of the consumer's preferences not only for those attributes, but also for other smart product characteristics. 


\section{Conclusions}

We are living in a world with an increasing number of autonomous products that can make small decisions by obtaining information about their environment and the personal preferences of the user. A high level of autonomy of a product can be useful and efficient, but it can also lead to greater intrusiveness. Together with privacy risk, intrusiveness is one of the main consumer concerns about the new connected products or those with Internet of things technologies. Therefore, it is important to examine what firms can do to reduce these negative perceptions of smart products.

In this paper, we have examined how firms can reduce the level of intrusiveness generated by the autonomy of smart home speakers. Our study has analyzed how the perceived interactivity of the product can reduce that negative effect, not only in a direct way, but also by moderating that effect. The research also proposes that interactivity can reduce the perceived intrusiveness of the product by increasing trust in the provider. The results confirm the two ways - direct and indirect - by which perceived interactivity can reduce intrusiveness. A high perception of interactivity involves a strong two-way communication, responsiveness, and perceived control. Therefore, increasing the perceived interactivity can help to reduce the effect that the level of autonomy has on intrusiveness. Firms can use the level of interactivity to offer consumers more information and communication with the product, which may increase the perceived control and ultimately reduce the perceived intrusiveness of the product. Therefore, as products become smarter and more autonomous, they should also become more interactive.

\section{Acknowledgments}

The authors want to thank the reviewers and the editor for their comments and suggestions to improve the manuscript. The authors wish to express their gratitude for financial support received from Ministerio de Economía y Competitividad MINECO ( ECO2017-83993-P), the Gobierno de Aragón and the European Social Fund (GENERES Group S-54_20R) and the Ayudas a Jóvenes Investigadores offered by Universidad de Zaragoza and Ibercaja (JIU-2018-SOC-08).

\section{Appendix A. Appendix: Questionnaire}

\section{Intrusiveness}

My smart home speaker is intrusive.

My smart home speaker is irritating.

My smart home speaker is indiscreet.

My smart home speaker is disturbing.

\section{Autonomy}

My smart home speaker determines itself how it conducts tasks.

My smart home speaker takes decisions by itself.

My smart home speaker takes the initiative.

My smart home speaker does things by itself.

\section{Two-way communication}

My smart home speaker facilitates two-way communication.

My smart home speaker gives me the opportunity to talk back.

My smart home speaker facilitates concurrent communication.

My smart home speaker enables conversation.

My smart home speaker does not encourage visitors to talk back. (Reverse).

My smart home speaker is effective in gathering visitors' feedback.

\section{Responsiveness}

My smart home speaker processed my input very quickly.

Getting information from my smart home speaker is very fast.

I was able to obtain the information I want without any delay.

When I interact with my smart home speaker, I felt I was getting instantaneous information.

My smart home speaker was very slow in responding to my request. (Reverse).

My smart home speaker answers my question immediately.

\section{Perceived control}

While I use my smart home speaker, I am always aware where I am doing.

While I use my smart home speaker, I always know how my smart home speaker will perform.

I know how to control my smart home speaker efficiently.

I can manage information and requests in my smart home speaker as I wish.

I can freely move through my smart home speaker menu.

Overall, I can control my smart home speaker well.

I feel that I have a great deal of control over my experience with my smart home speaker.

While using the service offered by the smart home speaker, my actions decide the kind of experiences I got.

\section{Trust}

I think that my home voice assistant provider is reliable.

I think that my home voice assistant provider keeps promises and commitments.

I think that my home voice assistant provider keeps customers' best interests in mind.

I feel confidence in my home voice assistant provider.

Perceived usefulness

Using IoT services would improve my work/life performance.

Using IoT services enhances my work/life effectiveness.

Using IoT services enables me to accomplish my work/life tasks more quickly.

Using IoT services help me get useful information for my work/life.

Using IoT services is very useful for me.

\section{References}

Abdullah, D., Jayaraman, K., Shariff, D. N., Bahari, K. A., \& Nor, N. M. (2017). The effects of perceived interactivity, perceived ease of use and perceived usefulness on online hotel booking intention: a conceptual framework. International Academic Research Journal of Social Science, 3 (1), 16-23. 
Accenture (2019). Smart Speaker Usage Booming Worldwide, Accenture Study Finds. https://newsroom.accenture.com/news/smart-speaker-usage-boomingworldwide-accenture-study-finds.htm?_ga=2.47431139.574316138. $1581001902-824273243.1579949286$.

Adapa, A., Nah, F. F. H., Hall, R. H., Siau, K., \& Smith, S. N. (2018). Factors influencing the adoption of smart wearable devices. International Journal of Human-Computer Interaction, 34(5), 399-409, https://doi.org/10.1080/ 10447318.2017.1357902.

Aggarwal, P., \& McGill, A. L. (2007). Is that car smiling at me? Schema congruity as a basis for evaluating anthropomorphized products. Journal of Consumer Research, 34(4), 468-479, https://doi.org/10.1086/518544.

Albrechtslund, A. (2008). Online social networking as participatory surveillance. First Monday, 3.

Ayyagari, R., Grover, V., \& Purvis, R. (2011). Technostress: technological antecedents and implications. MIS Quarterly, 831-858.

Baber, C. (1996). Humans, servants and agents: Human factors of intelligent products. Paper presented at the Conference on Artificial intelligence in Consumer and Domestic Products, London, https://doi.org/10.1049/ ic: 19961141.

Barwitz, N., \& Maas, P. (2018). Understanding the omnichannel customer journey: Determinants of interaction choice. Journal of Interactive Marketing, 43, 116-133, https://doi.org/10.1016/j.intmar.2018.02.001.

Bayus, B. L. (2013). Crowdsourcing new product ideas over time: An analysis of the Dell IdeaStorm community. Management Science, 59(1), 226-244, https://doi.org/10.1287/mnsc.1120.1599.

Benlian, A., Klumpe, J., \& Hinz, O. (2019). Mitigating the intrusive effects of smart home assistants by using anthropomorphic design features: A multimethod investigation. Information Systems Journal, Special Issue, https://doi.org/10.1111/isj.12243.

Boeck, H., Roy, J., Durif, F., \& Grégoire, M. (2011). The effect of perceived intrusion on consumers' attitude towards using an RFID-based marketing program. Procedia Computer Science, 5, 841-848, https://doi.org/10.1016/ j.procs.2011.07.116.

Broniarczyk, S. M., \& Griffin, J. G. (2014). Decision difficulty in the age of consumer empowerment. Journal of Consumer Psychology, 24(4), 608-625, https://doi.org/10.1016/j.jcps.2014.05.003.

Buhr, S. (2016). An Amazon Echo may be the key to solving a murder case. Retrieved from https://techcrunch.com/2016/12/27/an-amazon-echo-maybe-the-key-to-solving-a-murder-case/.

Carmines, E. G., \& Zeller, R. A. (1979). Reliability and validity assessment. Sage Publications.

Carvalho, A., \& Fernandes, T. (2018). Understanding customer brand engagement with virtual social communities: A comprehensive model of drivers, outcomes and moderators. Journal of Marketing Theory and Practice, 26(1-2), 23-37, https://doi.org/10.1080/10696679.2017. 1389241.

Chan, K. W., Li, S. Y., \& Zhu, J. J. (2015). Fostering customer ideation in crowdsourcing community: The role of peer-to-peer and peer-to-firm interactions. Journal of Interactive Marketing, 31, 42-62, https://doi.org/ 10.1016/j.intmar.2015.05.003.

Chattaraman, V., Kwon, W. S., Gilbert, J. E., \& Ross, K. (2019). Should AIbased, conversational digital assistants employ social-or task-oriented interaction style? A task-competency and reciprocity perspective for older adults. Computers in Human Behavior, 90, 315-330, https://doi.org/ 10.1016/j.chb.2018.08.048.

Cho, C. H. (2004). Effects of banner clicking and attitude toward the linked target ads on brand-attitude and purchase-intention changes. Journal of Global Academy of Marketing Science, 14(1), 1-16, https://doi.org/ 10.1080/12297119.2004.9707219.

Chuah, S. H. W., Rauschnabel, P. A., Krey, N., Nguyen, B., Ramayah, T., \& Lade, S. (2016). Wearable technologies: The role of usefulness and visibility in smartwatch adoption. Computers in Human Behavior, 65, 276-284, https://doi.org/10.1016/j.chb.2016.07.047.

Coursaris, C. K., \& Sung, J. (2012). Antecedents and consequents of a mobile website's interactivity. New Media \& Society, 14(7), 1128-1146, https://doi. org/10.1177/1461444812439552.

Cronin, M. J. (2010). Smart products, smarter services: Strategies for embedded control. Cambridge, U.K: Cambridge University Press.
Cyr, D., Head, M., \& Ivanov, A. (2009). Perceived interactivity leading to eloyalty: Development of a model for cognitive-affective user responses. International Journal of Human-Computer Studies, 67(10), 850-869, https://doi.org/10.1016/j.ijhcs.2009.07.004.

Davis, F. D. (1989). Perceived usefulness, perceived ease of use, and user acceptance of information technology. MIS Quarterly, 319-340, https://doi. org/10.2307/249008.

Deighton, J., \& Kornfeld, L. (2009). Interactivity's unanticipated consequences for marketers and marketing. Journal of Interactive Marketing, 23(1), 4-10, https://doi.org/10.1016/j.intmar.2008.10.001.

Delgado-Ballester, E. (2004). Applicability of a brand trust scale across product categories: a multigroup invariance analysis. European Journal of Marketing, Vol. 38(5/6), 573-592, https://doi.org/10.1108/03090560410529222.

Dennis, C., Merrilees, B., Jayawardhena, C., \& Wright, L. T. (2009). Econsumer behaviour. European Journal of Marketing, 43(9/10), 1121-1139, https://doi.org/10.1108/03090560910976393.

Dinev, T., Xu, H., Smith, J. H., \& Hart, P. (2013). Information privacy and correlates: An empirical attempt to bridge and distinguish privacy-related concepts. European Journal of Information Systems, 22(3), 295-316, https://doi.org/10.1057/ejis.2012.23.

Edwards, S. M., Li, H., \& Lee, J. H. (2002). Forced exposure and psychological reactance: Antecedents and consequences of the perceived intrusiveness of pop-up ads. Journal of Advertising, 31(3), 83-95, https://doi.org/10.1080/ 00913367.2002 .10673678$.

Etemad-Sajadi, R. (2016). The impact of online real-time interactivity on patronage intention: the use of avatars. Computers in Human Behavior, 61, 227-232, https://doi.org/10.1016/j.chb.2016.03.045.

Fan, L., Liu, X., Wang, B., \& Wang, L. (2017). Interactivity, engagement, and technology dependence: Understanding users' technology utilisation behaviour. Behaviour \& \& Information Technology, 36(2), 113-124, https://doi.org/10.1080/0144929X.2016.1199051.

Fernandes, T., \& Oliveira, E. (2020). Understanding consumers' acceptance of automated technologies in service encounters: Drivers of digital voice assistants adoption. Journal of Business Research, 122, 180-191, https:// doi.org/10.1016/j.jbusres.2020.08.058.

Fornell, C., \& Larcker, D. F. (1981). Evaluating structural equation models with unobservable variables and measurement error. Journal of Marketing Research, 18(1), 39-50, https://doi.org/10.1177/002224378101800104.

Gao, Q., Rau, P. L. P., \& Salvendy, G. (2010). Measuring perceived interactivity of mobile advertisements. Behaviour \& Information Technology, 29(1), 35-44.

Gartner (2016). Gartner Says Worldwide Spending on VPA-Enabled Wireless Speakers Will Top \$2 Billion by 2020. http://www.gartner.com/newsroom/ id/3464317.

Gefen, D. (2000). E-commerce: The role of familiarity and trust. Omega, 28(6), 725-737, https://doi.org/10.1016/S0305-0483(00)00021-9.

Gefen, D., Karahanna, E., \& Straub, D. W. (2003). Trust and TAM in online shopping: An integrated model. MIS Quarterly, 27(1), 51-90.

Geisser, S. (1974). A predictive approach to the random effects model. Biometrika, 61(1), 101-107, https://doi.org/10.1093/biomet/61.1.101.

Ghazal, M., Akmal, M., Iyanna, S., \& Ghoudi, K. (2016). Smart plugs: Perceived usefulness and satisfaction: Evidence from United Arab Emirates. Renewable and Sustainable Energy Reviews, 55, 1248-1259, https://doi. org/10.1016/j.rser.2015.07.096.

Hair, J. F., Ringle, C. M., \& Sarstedt, M. (2011). PLS-SEM: Indeed a silver bullet. Journal of Marketing Theory and Practice, 19(2), 139-151, https:// doi.org/10.2753/MTP1069-6679190202.

Hauk, J., \& Padberg, J. (2016). The customer in the center of digital transformation. Detecon Management Report 1/2016.

Henseler, J., Ringle, C. M., \& Sarstedt, M. (2015). A new criterion for assessing discriminant validity in variance-based structural equation modeling. Journal of the Academy of Marketing Science, 43(1), 115-135, https://doi. org/10.1007/s11747-014-0403-8.

Hérault, S., \& Belvaux, B. (2014). "Privacy paradox" et adoption de technologies intrusives Le cas de la géolocalisation mobile. Décisions Marketing, 67-82 https://www.jstor.org/stable/44820900.

Hoffman, D. L., \& Novak, T. P. (1996). Marketing in hypermedia computermediated environments: Conceptual foundations. Journal of Marketing, 60 (3), 50-68, https://doi.org/10.1177/002224299606000304. 
Hoffman, D. L., \& Novak, T. P. (2015). Emergent Experience and the Connected Consumer in the Smart Home Assemblage and the Internet of Things (August 20, 2015). Available at SSRN https://ssrn.com/ abstract $=2648786$. or , https://doi.org/10.2139/ssrn.2648786.

Hoffman, D. L., \& Novak, T. P. (2018). Consumer and object experience in the internet of things: An assemblage theory approach. Journal of Consumer Research, 44(6), 1178-1204, https://doi.org/10.1093/jcr/ucx105.

Holtrop, N., Wieringa, J. E., Gijsenberg, M. J., \& Verhoef, P. C. (2017). No future without the past? Predicting churn in the face of customer privacy. International Journal of Research in Marketing, 34(1), 154-172.

Hood, K. M., Shanahan, K. J., Hopkins, C. D., \& Lindsey, K. K. (2015). The influence of interactivity on visit and purchase frequency: The moderating role of website informational features. Journal of Internet Commerce, 14(3), 294-315, https://doi.org/10.1080/15332861.2015.1084137.

Horning, M. A. (2017). Interacting with news: Exploring the effects of modality and perceived responsiveness and control on news source credibility and enjoyment among second screen viewers. Computers in Human Behavior, 73, 273-283, https://doi.org/10.1016/j.chb.2017.03.023.

Hsu, M. H., Chang, C. M., Chu, K. K., \& Lee, Y. J. (2014). Determinants of repurchase intention in online group-buying: the perspectives of DeLone \& McLean IS success model and trust. Computers in Human Behavior, 36(1), 234-245.

Hsu, C. L., \& Lin, J. C. C. (2016). An empirical examination of consumer adoption of internet of things services: Network externalities and concern for information privacy perspectives. Computers in Human Behavior, 62, 516-527.

Keh, H. T., \& Pang, J. (2010). Customer reactions to service separation. Journal of Marketing, 74(2), 55-70, https://doi.org/10.1509/jm.74.2.55.

Kidd, C. D. (2008). Designing for long-term human-robot interaction and application to weight loss. Thesis supervised by Breazeal, C., accepted at Massachusetts Institute of Technology, Cambridge, MA.

Kim, J., Spielmann, N., \& McMillan, S. J. (2012). Experience effects on interactivity: Functions, processes, and perceptions. Journal of Business Research, 65(11), 1543-1550, https://doi.org/10.1016/j.jbusres. 2011.02.038.

Klumpe, J., Koch, O. F., \& Benlian, A. (2018). How pull vs. push information delivery and social proof affect information disclosure in location based services. Electronic Markets, 30, 569-586, https://doi.org/10.1007/s12525018-0318-1.

Koo, D. M., \& Choi, Y. Y. (2010). Knowledge search and people with high epistemic curiosity. Computers in Human Behavior, 26(1), 12-22, https:// doi.org/10.1016/j.chb.2009.08.013.

Krafft, M., Arden, C. M., \& Verhoef, P. C. (2017). Permission marketing and privacy concerns-Why do customers (not) grant permissions? Journal of Interactive Marketing, 39, 39-54, https://doi.org/10.1016/j.intmar.2017 .03 .001 .

Landwehr, J. R., McGill, A. L., \& Herrmann, A. (2011). It's got the look: The effect of friendly and aggressive "facial" expressions on product liking and sales. Journal of Marketing, 75(3), 132-146, https://doi.org/10.1509/ jmkg.75.3.132.

Lee, D., Moon, J., Kim, Y. J., \& Mun, Y. Y. (2015). Antecedents and consequences of mobile phone usability: Linking simplicity and interactivity to satisfaction, trust, and brand loyalty. Information \& Management, 52 (3), 295-304, https://doi.org/10.1016/j.im.2014.12.001.

Lee, H. H., Fiore, A. M., \& Kim, J. (2006). The role of the technology acceptance model in explaining effects of image interactivity technology on consumer responses. International Journal of Retail \& Distribution Management, 34(8), 621-644, https://doi.org/10.1108/095905506106 75949.

Lee, T. (2005). The impact of perceptions of interactivity on customer trust and transaction intentions in mobile commerce. Journal of Electronic Commerce Research, 6(3), 165.

Leung, E., Paolacci, G., \& Puntoni, S. (2018). Man versus machine: Resisting automation in identity-based consumer behavior. Journal of Marketing Research, 55(6), 818-831, https://doi.org/10.1177/0022243718818423.

Liang, T. P., Ho, Y. T., Li, Y. W., \& Turban, E. (2011). What drives social commerce: The role of social support and relationship quality. International Journal of Electronic Commerce, 16(2), 69-90, https://doi.org/10.2753/ JEC1086-4415160204.
Lin, H. F. (2007). The impact of website quality dimensions on customer satisfaction in the B2C e-commerce context. Total Quality Management and Business Excellence, 18(4), 363-378, https://doi.org/10.1080/14783360701231302.

Liu, Y. (2003). Developing a scale to measure the interactivity of websites. Journal of Advertising Research, 43(2), 207-216, https://doi.org/10.2501/ JAR-43-2-207-216.

Liu, Y., \& Shrum, L. J. (2002). What is interactivity and is it always such a good thing? Implications of definition, person, and situation for the influence of interactivity on advertising effectiveness. Journal of Advertising, 31(4), 53-64, https://doi.org/10.1080/00913367.2002.10673685.

Luor, T. T., Lu, H. P., Yu, H., \& Lu, Y. (2015). Exploring the critical quality attributes and models of smart homes. Maturitas, 82(4), 377-386, https:// doi.org/10.1016/j.maturitas.2015.07.025.

Malhotra, N. K., Kim, S. S., \& Agarwal, J. (2004). Internet users' information privacy concerns (IUIPC): The construct, the scale, and a causal model. Information Systems Research, 15(4), 336-355, https://doi.org/10.1287/ isre. 1040.0032 .

Mani, Z., \& Chouk, I. (2017). Drivers of consumers' resistance to smart products. Journal of Marketing Management, 33(1/2), 76-97, https://doi. org/10.1080/0267257X.2016.1245212.

Mani, Z., \& Chouk, I. (2019). Impact of privacy concerns on resistance to smart services: Does the 'big brother effect' matter? Journal of Marketing Management, 32(15/16), 1460-1479, https://doi.org/10.1080/0267257X. 2019.1667856.

McCroskey, J. C., \& Teven, J. J. (1999). Goodwill: A reexamination of the construct and its measurement. Communications Monographs, 66(1), 90-103, https://doi.org/10.1080/03637759909376464.

McLean, G., \& Osei-Frimpong, K. (2019). Hey Alexa... examine the variables influencing the use of artificial intelligent in-home voice assistants. Computers in Human Behavior, 99, 28-37, https://doi.org/10.1016/j. chb.2019.05.009.

McMillan, S., \& Hwang, J. S. (2002). Measures of perceived interactivity: An exploration of the role of direction of communication, user control, and time in shaping perceptions of interactivity. Journal of Advertising, 31(3), 29-42, https://doi.org/10.1080/00913367.2002.10673674.

Merrilees, B., \& Fry, M. L. (2002). Corporate branding: A framework for eretailers. Corporate Reputation Review, 5(2-3), 213-225, https://doi.org/ 10.1057/palgrave.crr.1540175.

Mollen, A., \& Wilson, H. (2010). Engagement, telepresence and interactivity in online consumer experience: Reconciling scholastic and managerial perspectives. Journal of Business Research, 63(9-10), 919-925, https:// doi.org/10.1016/j.jbusres.2009.05.014.

Morgan, R. M., \& Hunt, S. D. (1994). The commitment-trust theory of relationship marketing. Journal of Marketing, 58(3), 20-38, https://doi.org/ 10.1177/002224299405800302.

Moriuchi, E. (2019). Okay, Google!: An empirical study on voice assistants on consumer engagement and loyalty. Psychology \& Marketing, 36(5), 489-501, https://doi.org/10.1002/mar.21192.

Mosteller, J., \& Poddar, A. (2017). To share and protect: Using regulatory focus theory to examine the privacy paradox of consumers' social media engagement and online privacy protection behaviors. Journal of Interactive Marketing, 39, 27-38, https://doi.org/10.1016/j.intmar.2017.02.003.

Novak, T. P., \& Hoffman, D. L. (2019). Relationship journeys in the internet of things: A new framework for understanding interactions between consumers and smart objects. Journal of the Academy of Marketing Science, 47 (2), 216-237, https://doi.org/10.1007/s11747-018-0608-3.

Nunnally, J. C. (1978). Psychometric Theory. New York, NY: McGraw-Hill.

Pavlou, P. A. (2003). Consumer acceptance of electronic commerce: Integrating trust and risk with the technology acceptance model. International Journal of Electronic Commerce, 7(3), 101-134, https://doi.org/10.1080/10864415. 2003.11044275.

Plangger, K., \& Montecchi, M. (2020). Thinking beyond privacy calculus: Investigating reactions to customer surveillance. Journal of Interactive Marketing, 50, 32-44, https://doi.org/10.1016/j.intmar.2019.10.004.

Qiu, L., \& Benbasat, I. (2009). Evaluating anthropomorphic product recommendation agents: A social relationship perspective to designing information systems. Journal of Management Information Systems, 25(4), 145-181, https://doi.org/10.2753/MIS0742-1222250405. 
Rijsdijk, S. A., \& Hultink, E. J. (2003). Honey, have you seen our hamster? Consumer evaluations of autonomous domestic products. Journal of Product Innovation Management, 20(3), 204-216, https://doi.org/10.1111/ 1540-5885.2003003.

Rijsdijk, S. A., \& Hultink, E. J. (2009). How today's consumers perceive tomorrow's smart products. Journal of Product Innovation Management, 26 (1), 24-42, https://doi.org/10.1111/j.1540-5885.2009.00332.x.

Rijsdijk, S. A., Hultink, E. J., \& Diamantopoulos, A. (2007). Product intelligence: Its conceptualization, measurement and impact on consumer satisfaction. Journal of the Academy of Marketing Science, 35(3), 340-356, https://doi.org/10.1007/s11747-007-0040-6.

Roy, S. K., Balaji, M. S., Sadeque, S., Nguyen, B., \& Melewar, T. C. (2017). Constituents and consequences of smart customer experience in retailing. Technological Forecasting and Social Change, 124, 257-270, https://doi. org/10.1016/j.techfore.2016.09.022.

Saeed, K. A., \& Abdinnour-Helm, S. (2008). Examining the effects of information system characteristics and perceived usefulness on post adoption usage of information systems. Information \& Management, 45 (6), 376-386, https://doi.org/10.1016/j.im.2008.06.002.

Silaban, H. F., Hasudungan, S., Nadapdap, S. L. Y., Situmeang, F., \& Situmeang, R. (2019, March). Improving customer's willingness to buy: choosing the right salesperson activities. Journal of Physics: Conference Series (Vol. 1175, no. 1, p. 012199). IOP Publishing.

Singh, J. J., Iglesias, O., \& Batista-Foguet, J. M. (2012). Does having an ethical brand matter? The influence of consumer perceived ethicality on trust, affect and loyalty. Journal of Business Ethics, 111(4), 541-549, https://doi.org/ 10.1007/s10551-012-1216-7.

Song, J. H., \& Zinkhan, G. M. (2008). Determinants of perceived web site interactivity. Journal of Marketing, 72(2), 99-113, https://doi.org/10.1509/ jmkg.72.2.99.

Stone, M. (1974). Cross-validatory choice and assessment of statistical predictions. Journal of the Royal Statistical Society, 36(2), 111-147, https://doi.org/10.1111/j.2517-6161.1974.tb00994.x.

Sun, Y., Fang, S., \& Hwang, Y. (2019). Investigating privacy and information disclosure behavior in social electronic commerce. Sustainability, 11(12), 3311, https://doi.org/10.3390/su11123311.

Thellman, S., Silvervarg, A., Gulz, A., \& Ziemke, T. (2016, September). Physical vs. virtual agent embodiment and effects on social interaction. International Conference on Intelligent Virtual Agents. Cham: Springer, 412-415, https://doi.org/10.1007/978-3-319-47665-0_44.

To, C. K. M., Yee, R. W., Mok, P. Y., Chau, K. P., Wong, M. C., \& Cheung, N. M. (2018). Collaboration reasoning or social heuristics? Value proposition validity in omnium-gatherum business models. Journal of Business Research, 88, 550-559, https://doi.org/10.1016/j.jbusres.2018.01.062.

Touzani, M., Charfi, A. A., Boistel, P., \& Niort, M. C. (2018). Connecto ergo sum! An exploratory study of the motivations behind the usage of connected objects. Information \& Management, 55(4), 472-481, https://doi.org/ 10.1016/j.im.2017.11.002.

Van den Broeck, E., Zarouali, B., \& Poels, K. (2019). Chatbot advertising effectiveness: When does the message get through? Computers in Human Behavior, 98, 150-157, https://doi.org/10.1016/j.chb.2019.04.009.

Veletsianos, G., \& Navarrete, C. (2012). Online social networks as formal learning environments: Learner experiences and activities. The International Review of Research in Open and Distributed Learning, 13(1), 144-166, https://doi.org/10.19173/irrodl.v13i1.1078.

Verhoef, P. C., Stephen, A. T., Kannan, P. K., Luo, X., Abhishek, V., \& Andrews, M., et al (2017). Consumer connectivity in a complex, technology-enabled, and mobile-oriented world with smart products. Journal of Interactive Marketing, 40, 1-8, https://doi.org/10.1016/j. intmar.2017.06.001.

Wang, K. Y., Chih, W. H., \& Hsu, L. C. (2020). Building brand community relationships on Facebook Fan pages: The role of perceived interactivity. International Journal of Electronic Commerce, 24(2), 211-231, https://doi. org/10.1080/10864415.2020.1715532.

Waytz, A., Heafner, J., \& Epley, N. (2014). The mind in the machine: Anthropomorphism increases trust in an autonomous vehicle. Journal of Experimental Social Psychology, 52, 113-117, https://doi.org/10.1016/j. jesp.2014.01.005.

Wu, G., \& Wu, G. (2006). Conceptualizing and measuring the perceived interactivity of websites. Journal of Current Issues \& Research in Advertising, 28(1), 87-104, https://doi.org/10.1080/10641734.2006.10505193.

Wueest, C. (2017). A guide to the security of voice-activated smart speakers. An ISTR Special Report, November 2017.

$\mathrm{Xu}$, H., \& Gupta, S. (2009). The effects of privacy concerns and personal innovativeness on potential and experienced customers' adoption of location-based services. Electronic Markets, 19(2-3), 137-149, https://doi. org/10.1007/s12525-009-0012-4.

Yadav, M. S., \& Varadarajan, R. (2005). Interactivity in the electronic marketplace: an exposition of the concept and implications for research. Journal of the Academy of Marketing Science, 33(4), 585-603, https://doi. org/10.1177/0092070305278487.

Yang, H., Lee, H., \& Zo, H. (2017). User acceptance of smart home services: an extension of the theory of planned behavior. Industrial Management \& Data Systems, 117(1), 68-89, https://doi.org/10.1108/IMDS-01-2016-0017.

Yim, M. Y. C., \& Park, S. Y. (2019). "I am not satisfied with my body, so I like augmented reality (AR)": Consumer responses to AR-based product presentations. Journal of Business Research, 100, 581-589, https://doi. org/10.1016/j.jbusres.2018.10.041.

Zeng, F., Ye, Q., Li, J., \& Yang, Z. (2021). Does self-disclosure matter? A dynamic two-stage perspective for the personalization-privacy paradox. Journal of Business Research, 124, 267-275. 